\title{
RETRACTION
}

\section{CD133 and DNA-PK regulate MDR1 via the PI3K- or Akt-NF-кB pathway in multidrug-resistant glioblastoma cells in vitro}

G Xi, E Hayes, R Lewis, S Ichi, B Mania-Farnell, K Shim, T Takao, E Allender, CS Mayanil and T Tomita

Oncogene (2016) 35, 5576; doi:10.1038/onc.2016.64; published online 5 September 2016

Retraction to: Oncogene (2016) 35, 241-250; doi:10.1038/ onc.2015.78; published online 30 March 2015

The authors wish to retract this paper owing to the use of misidentified cell lines in the study. According to the description on the ATCC official website and reanalysis of the STR for cell line authentication, two misidentified glioblastoma cell lines, U251MG and U373MG, were used in this work. Based on recent literature (Torsvik et al. Cancer Med 2014; 3: 812-824), these two lines are thought to be cross-contaminated. Any data from misidentified or cross-contaminated cell lines are misleading-rendering conclusions incorrect.

G Xi, E Hayes, R Lewis, S Ichi, B Mania-Farnell, T Takao and CS Mayanil agreed to this retraction. $\mathrm{K}$ Shim, E Allender and T Tomita could not be reached to comment on the retraction.

The authors declare no conflict of interest.

\section{Rituximab inhibits the constitutively activated PI3K-Akt pathway in B-NHL cell lines: involvement in chemosensitization to drug-induced apoptosis}

E Suzuki, K Umezawa and B Bonavida

Oncogene (2016) 35, 5576; doi:10.1038/onc.2016.207; published online 27 June 2016

Retraction to: Oncogene (2007) 26, 6184-6193; doi:10.1038/sj.onc. 1210448; published online 9 April 2007
As per the request of the authors, the Editors and Publisher have agreed to retract this paper due to the data irregularities, which result in the conclusions drawn not being fully supported. 